\title{
A Leaf Lamina Compression Method for Estimating Turgor Pressure
}

\author{
Adonai Gimenez Calbo ${ }^{1}$, Marcos David Ferreira, and \\ José Dalton Cruz Pessoa \\ Embrapa Agricultural Instrumentation, Brazilian Agricultural Research \\ Corporation, rua Quinze de Novembro, 1452, P.O. Box 741, São Carlos, \\ SP, 13560-970, Brazil
}

Additional index words. Brassica oleracea, Chichorium endivia, Lactuca sativa, irrigation scheduling, turgor pressure, vegetables, wiltmeter

\begin{abstract}
A portable wiltmeter instrument to estimate leaf turgor pressure according to an adaptation of the flattening method was developed. In the instrument, a flexible inflating membrane presses the leaf against a flattening plate having small orifices surrounded by a finely engraved network of obtuse indentations through which air flow is delivered. During a measurement, as the compression builds up, the leaf is progressively molded against the flattening plate, and as a consequence, the air flow $(x)$ crossing the plate is reduced toward zero. The smallest leaf compression $\left(p_{0}\right)$ that blocks the air passage is an estimate of the leaf turgor. Wiltmeter measurements were compared with pressure probe measurements of cell turgor pressure in detached leaves of lettuce (Lactuca sativa L.), kale (Brassica oleracea L. var. Acephala), and chicory (Chichorium endivia L.), which were allowed to suffer diverse levels of wilting caused by transpiration. Such observed wiltmeter readings were a little lower than the cell turgor pressure measured with a pressure probe; the regression coefficients between these methods were: 1.156 for lettuce, 1.13 for kale, and $\mathbf{1 . 0 3 6}$ for chicory. This portable quantitative procedure to measure leaf firmness has potentially valuable applications related to postharvest and field plant physiology studies.
\end{abstract}

Leaf cell turgor pressure is a water status variable related to firmness, growth, and with the consumer perception of wilting and freshness. Turgor pressure measurements are usually made at a laboratory using laborious procedures. With the pressure probe technique, for example, cell turgor pressure is estimated after impaling the probe capillary into plant cells within plant tissues (Hüsken et al., 1978; Nonami et al., 1987). Typically a pressure probe is made of an oil-filled microcapillary connected to a coupling chamber having a pressure transducer. In a measurement, after the capillary is impaled into a cell, the lowviscosity oil transmits cell fluid pressure to the pressure transducer. Next, using a micrometrical piston system (Nonami et al., 1987) or using a thermoelastic pressurization system (Pessoa and Calbo, 2004), the oil/water meniscus is returned to the preimpalement position and, at this point, the transduced cell turgor pressure is measured.

In the field, plant water status is frequently accessed using the pressure chamber (Scholander et al., 1964). The variable measured by this instrument, however, is not turgor pressure but the complementary air pressure, which is needed to extract sap water out of the petiole of leaves subjected to an air pressure

Received for publication 3 Sept. 2009. Accepted for publication 9 Dec. 2009

We are indebted to Mr. João Batista Gomes from Embrapa Vegetables for building preliminary models of the portable instrument used to measure leaf firmness.

${ }^{1}$ To whom reprint requests should be addressed; e-mail adonai@cnpdia.embrapa.br. cell turgor pressure response in the patch clamp is approached with aid of an intricate mathematical approximation applied to a data set that presents a delayed time line response that can be as large as $4 \mathrm{~h}$ on sunny days.

For convex-shaped organs such as many fruits, a flattening method is being used to estimate the turgor-dependent pressure firmness for several applications, including some new fruit firmness half-life determinations (Caron et al., 2003; Kluge et al., 1999; Nizio et al., 2008). The flattening method was developed initially to model a grape berry as if it were a thin-walled balloon filled with pressurized water (Berstein and Lustig, 1981; Bernstein and Lustig, 1985). According to this model, an external force applied with a transparent plate flattens a fruit surface area in which the value is equal to the turgor pressure multiplied by the fruit flattened area. More recently (Lintilhac and Outwater, 1998; Lintilhac et al., 2000), an analogous thin-walled balloon approach was used to measure epidermal cells under the microscope with a procedure named ball tonometry.

Using a more general plant physiology reasoning, the flattening procedure was extended to estimate cell turgor pressure of other convex fruits and vegetables covered by soft dermal tissues (Calbo and Calbo, 1989; Calbo and Nery, 1995; Calbo et al., 1995) composed of thin-walled poliedric cells that cover the internal plant cellular structure made out of parenchymatous cells having deformable intercellular air volumes. Accordingly, for some regular cellular lattices, it was demonstrated that there is a simple mathematical relation between the flattening pressure and cell turgor (Calbo and Nery, 2001). In these lattice models, the flattening pressure and the cell turgor pressure are related by a cell compression ratio, whose magnitude ranges from zero to one depending on remaining intercellular air volume fraction during mechanical axial compression assays.

A first attempt to develop a portable instrument to measure the leaf turgor using the flattening method involved a setup having a plain rigid base over which the leaf was compressed by a piston flattening plate, whose surface was finely indented around a few small air flow outlet orifices (Calbo, 1991). For a measurement, the leaf was progressively compressed by this piston and the reduction of applied air flow, filtered between the leaf and the flattening plate, was used as a criterion of leaf flattening that was used to estimate the leaf turgor. The instrument was simple and quantitative, but the piston borders caused leaf deformation marks, especially in thicker leafs, and these marks were considered to be a potential cause of leaf turgor underestimation in thick leaves.

In this communication, a portable instrument that makes use of the flattening method to estimate the leaf turgor pressure status, without causing leaf indentation marks, is presented for possible use in postharvest and field-oriented plant physiology studies. This wiltmeter instrument performance was then considered mainly with reference to the pressure probe 
method to measure cell turgor in leaves of vegetable crops.

\section{Materials and Methods}

The instrument in Figure 1 enables the use of a leaf lamina compression method adapta-

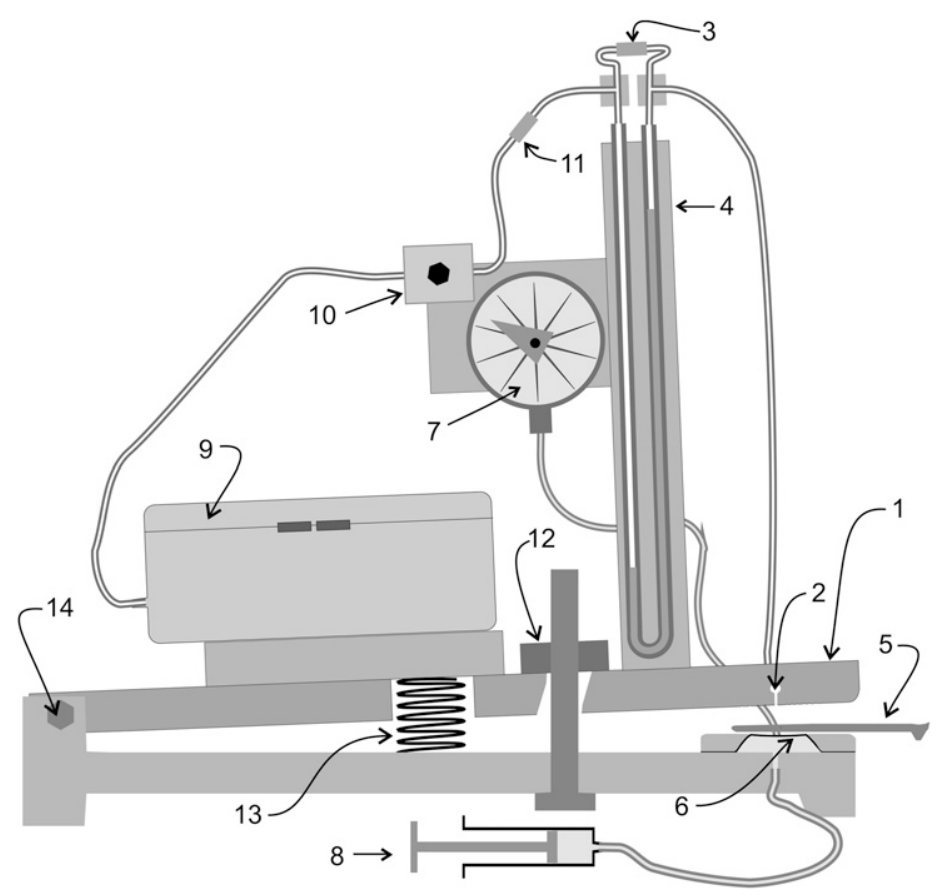

Fig. 1. Scheme of a wiltmeter instrument to measure leaf turgor pressure using the flattening method implemented with aid of an air flow attenuation procedure. The system is composed of a flattening plate with a slightly granular base (1) having centralized microair inlet orifices (2); an air restriction (3) flow meter in which air flow is read in a U tube manometer (4) where the progress of the leaf (5) flattening is followed; a flexible membrane fixed in the instrument base (6) is the element used to compress the leaf against the flattening plate while pressure, read in the manometer (7), is being applied with a waterfilled syringe (8). The air flow needed for this flattening attenuation mechanism is fed by an air compressor (9) coupled to a pressure regulator (10) and an inlet air restriction (11). During the measurement, the leaf remains clamped with aid of a bolt screw nut (12), while the spring (13) eases instrument opening and leaf freeing by forcing the flattening plate movement around the axle (14). anism. The air flow source was composed of an air compressor [Fig. 1 (9)], an air escape pressure regulator [Fig. 1 (10)], and an inlet air flow restriction [Fig. 1 (11)]. The membrane hydraulic leaf compressing mechanism, on the other hand, was made with a sandwiched membrane [Fig. 1 (6)] fixed at the instrument base and works with water introduction to press the leaf against the flattening plate while this applied pressure is measured in a manometer [Fig. 1 (7)].

The air flow source delivers an air inlet pressure $\left(\Delta p_{0}\right)$ of $\approx 6 \mathrm{kPa}$. Of this pressure, while the instrument is open, $\approx 4 \mathrm{kPa}$ is dissipated at the inlet air restriction [Fig. 1 (11)] $R_{I}$ and $2.0 \mathrm{kPa}$ at the flow meter restriction [Fig. 1 (3)] $R_{2}$. At this condition, the flowmeter reading is $200 \mathrm{~mm}$ for an air flow of $90 \mathrm{~mL} \cdot \mathrm{min}^{-1}$. For practical use, this inlet air pressure is obtained by simple adjustment of the pressure regulator knob [Fig. 1 (10)] at 200 $\mathrm{mm}$ in the flowmeter manometer of the opened wiltmeter.

Measurement involves fixing the leaf [Fig. 1 (5)] with the screw nut [Fig. 1 (12)] and subjecting the leaf to a progressive compression against the flattening plate [Fig. 1 (1)] with the syringe [Fig. 1 (8)]. As the applied pressure increases, the leaf is progressively molded against the flattening plate while the air flow is attenuated down to zero in this air compression ramp-up assay.

Theoretical considerations. A quadratic model [Eq. (1)] generates an approximation for the nonlinear relation between the applied leaf compression $(p)$ and the air flow $(x)$ for $x$ values close to zero (Fig. 2).

$$
p=p_{0}-A x+B x^{2}
$$

In this equation, $p$ is the applied pressure, $x$ is the air flow, $p_{0}$ is the estimated applied pressure at the intercept $\left(x_{0}=0\right)$, whereas $A$
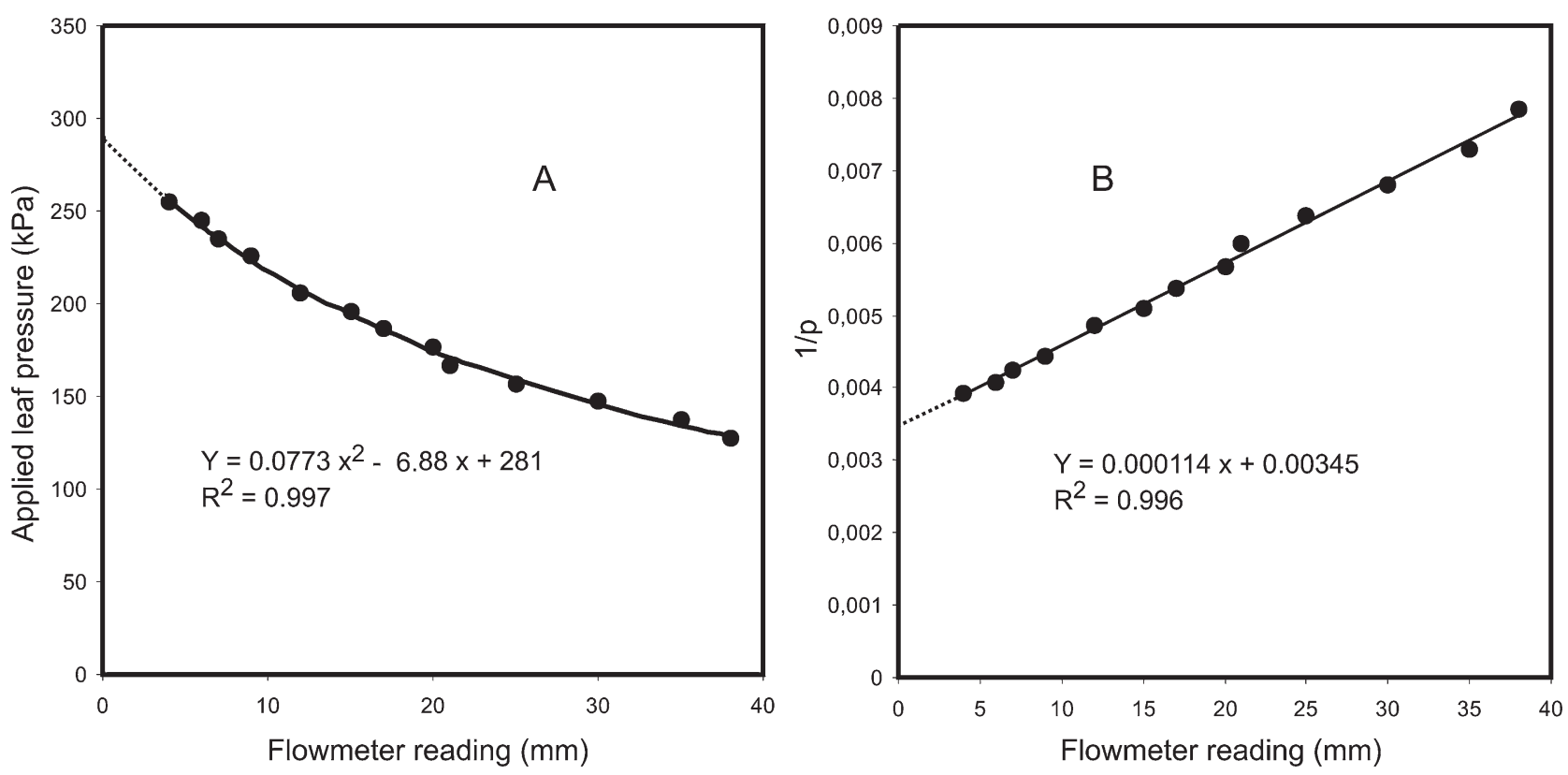

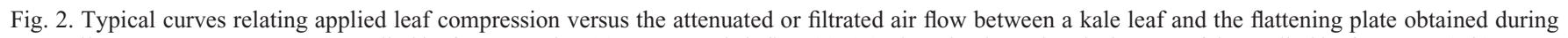
a wiltmeter measurement. (A) Applied leaf compression $(p)$ versus read air flow $(x)$. (B) Linearization using the inverse of the applied leaf pressure $(1 / p)$ versus read air flow $(x)$. 
and $B$ are fitting parameters. If experimental data could be taken even closer to zero, then a linear approximation would also be valid and in this case, in the quadratic term of Eq. [1], could be regarded as negligible.

Another simple instrument working approximation to estimate the applied pressure at the intercept $\left(p_{0}\right)$ is by an inverse linearization procedure (Calbo et al., 1989); in this case, the air flow $(x)$ and applied leaf pressure ( $p)$ are given by Eq. [2].

$$
1 / p=\left(\alpha x / p_{\text {air }}+1\right) / p_{0}
$$

where $p$ is the applied pressure, $x$ is the air flow, $p_{0}$ is the estimated applied pressure at the intercept $\left(x_{0}=0\right), \alpha$ is a leaf strain parameter, and $p_{\text {air }}$ is the wiltmeter adjusted inlet air pressure.

In a more simplified way, Eq. [2] can also be written as:

$$
1 / p=\left(C_{f} x+1\right) / p_{0}
$$

where $C_{f}$ is:

$$
C_{f}=\alpha / p_{\text {air }}
$$

Eqs. [3] and [4] are linearization approximations of the actual nonlinear relation between $p$ and $x$, which are valuable for $x$ values much smaller than the instrument open air flow $x_{0}$

$$
x<<x_{0}=\Delta p_{0} /\left(R_{1}+R_{2}\right)
$$

For practical purposes, quadratic and linearized approximations can be applied for $x$ values in the range between $x_{0} / 100$ and $x_{0} / 5$. For the linearized model, in particular, it is possible to calculate the leaf flattening pressure $\left(p_{0}\right)$ based on a single pressure reading taken at a specified air flow value $x_{j}$ using the coefficient $w$ calculated with Eq. [6].

$$
w=p_{0} / p_{j}=C_{f} x_{j}+1
$$

Correspondent $w$ coefficients can also be calculated for the quadratic approximating method [Eq. (1)]:

$$
w=p_{0} / p_{j}=p_{0} /\left(p_{0}-A x_{j}+B x_{j}^{2}\right)
$$

If the quadratic term of Eq. [1] is disregarded as insignificant, then $w$ could alternatively be expressed as:

$$
w=p_{0} / p_{j}=p_{0} /\left(p_{0}-A x_{j}\right)
$$

Reading procedures. The leaf pressure $\left(p_{0}\right)$ can be measured with methods that are slightly different from the basic instrument procedure (Calbo and Pessoa, 2009), in which the $x$ is reduced to zero during the $p_{0}$ estimate. This procedure, however, generates overestimated values in some cases and to overcome this possibility, the following leaf turgor pressure $\left(p_{0}\right)$ reading procedures can be considered:

1) Rapid reading using the following steps: a) The pressure regulator knob [Fig. 1 (10)] is unscrewed; b) ethanol is added to the flowmeter up to half of the manometer height; c) the air compressor [Fig. 1 (9)] is turned on; d) the pressure regulator knob [Fig. 1 (10)] is adjusted to obtain a $200-\mathrm{mm}$ reading at the flowmeter [Fig. 1 (4)]; e) the leaf is clamped to the wiltmeter using the screw nut [Fig. 1 (12)] without tightening; f) the leaf is then slowly compressed using the syringe [Fig. 1 (8)] up to the flowmeter [Fig. 1 (4)] reading declines down to $4 \mathrm{~mm}$ and at which point the manometer reading [Fig. $1(7)]\left(p_{x I}\right)$ is registered. The value $p_{x 1}$ read at $4 \mathrm{~mm}$ is the rapid uncorrected leaf flattening pressure estimate of the plant water status.

2) Quadratic approximation according to the following sequence: a) Steps a to e of the rapid procedure are used as before; b) the leaf is compressed slowly with the syringe [Fig. $1(8)]$ to reduce the flowmeter [Fig. 1 (4)] reading to $16 \mathrm{~mm}$ and the pressure at the manometer [Fig. 1 (7)] is read; c) the leaf is further compressed to obtain flowmeter readings of, for example, $12,8,4$, and $0 \mathrm{~mm}$, in which air fluxes new pressure readings are taken; d) the estimate of the intercept $\left(p_{0}\right)$ is obtained from the plot of $p$ versus $x$ using a quadratic equation fitting.

3) Linearized approximation according to the following sequence: a) Steps a to c from the quadratic approximation procedure are used to obtain pressure measurements at different air fluxes; b) Eq. [3] is fitted to the data to estimate the leaf firmness $\left(p_{0}\right)$.

4) Coefficient corrected approximation: All steps of the rapid procedure are followed and the leaf firmness $p_{0}$ is calculated using the coefficient $w$, which should have been previously obtained for similar leaves using Eq. [6].

Instrument maintenance. Before use, the flattening plate and the compressing membrane should be cleaned with a soft towel and neutral detergent. The instrument should also be checked for leakages, activity done with the instrument opened, using the pump on and the air flow set to $200 \mathrm{~mm}$ in the flowmeter manometer. In this condition, closing the air outlet orifices [Fig. 1 (2)] by pressing the finger against the flattening plate should cause the air flow to drop rapidly to zero. If the air flow drops down to zero, the instrument is free from leakages and ready to use.

Cell turgor pressure measurement. Leaf flattening pressure estimates were gauged against leaf cell turgor pressure measurements made with the pressure probe method (Hüsken et al., 1978; Nonami et al., 1987). The used pressure probe had a pressure transducer connected to a hermetic liquid-filled chamber, which was coupled at one side to a pressurizing screw-driven syringe and at the other side to a low-viscosity oil-filled measuring microcapillary. Soon after the capillary tip penetrates a cell, inside the leaf, the low-viscosity oil is rapidly pushed back by the cell fluid contained under turgor pressure inside the elastic plant cell wall. Turgor pressure was then read after having returned the capillary oil/water meniscus back its initial tip position by increasing the fluid pressure inside the pressure probe with aid of the syringe piston advancement.

To start a measurement, the capillary was slightly pressurized to make the oil appear at the capillary tip. The leaf was then moved slowly toward the capillary and measurement is made in palisadic parenchyma cells after the leaf penetration from the adaxial side. This procedure is relatively simple because new cell impalement is always followed by a transient oil/water meniscus movement.

Capillaries $\approx 140 \mathrm{~mm}$ long having a conical tip with an external diameter of 5 to 10 $\mu \mathrm{m}$ were used for the pressure probe measurements. These capillaries were produced from hematological borosilicate tubes $70 \mathrm{~mm}$ long and $1.0 \mathrm{~mm}$ wide (external diameter) in a three-step procedure: 1) hand pulling in a 20-mm wide flame reduced the tube external diameter to $\approx 150 \mu \mathrm{m} ; 2$ ) using a dragging weight of $25 \mathrm{~g}$, these intermediary capillaries were further pulled into an electrically heated coil where the capillary conical tip was formed by fusion; and 3) the capillary was positioned at an angle of $\approx 40^{\circ}$ and touched against a fine rotating grading wheel to open the heat-sealed capillary tip. These capillaries with bezel-shaped tips were then filled with low-viscosity oil and fixed to the pressure probe for measurement.

For capillary impalement, the leaf was fixed to a curved layer of plastic putty adhered to the micromanipulator front, which was moved toward the stationary capillary tip for leaf cell impalement.

Plant material. Crisp lettuce (Lactuca sativa L.), kale (Brassica oleracea L. var. acephala), and chicory (Cichorium endivia L.) leaves were harvested in the morning, placed in plastic bags, and brought to the São Carlos Embrapa Instrumentation Laboratory, where temperature was kept between 22 to $26^{\circ} \mathrm{C}$ and relative humidity ranged from $50 \%$ to $70 \%$ according to a ventilated wet bulb psychrometer reading.

Measurements were made in regular leaf areas, avoiding surfaces with large veins and mechanical injuries. These healthy leaves were taken excluding external dehydrated and nonexpanded internal leaves. Additionally, before measurements, any water droplets or visible dust were removed from the adaxial leaf surface with a soft paper towel.

Water status evaluation. Leaf water status changes were induced by placing individual leaves over the bench to speed the water loss and wilting. Measurements were made in the adaxial face, near the leaf border (less than $20 \mathrm{~mm}$ ). Pressure reading sampling with these two instruments were done as follows: For the pressure probe, each sample data was the average pressure of at least three palisadic cell pressure readings, whereas for the wiltmeter, each leaf was represented by a single reading. Measurements were done in leaves ranging from recently harvested turgidity to visibly wilted leaves. The obtained data for the studied leaf vegetables were compared by use of linear regression analysis. In the pressure probe measurement, especially for chicory, the occurrence of latex capillary tip plugging was a frequent difficulty that was overcome with 
pressure probe capillary replacement followed by measurements with a pressure probe and wiltmeter in new leaf samples.

\section{Results and Discussion}

During readings in lettuce, kale, and chicory, the wiltmeter instrument caused no leaf damage, except some eventual small marks in larger veins. This portable instrument is suitable for field use, where it can be used to read clean leaf surfaces. As a consequence, in some dusty environments, it is usually necessary to remove leaf-adhered particles with a soft towel. Similarly, in moist environments, it is necessary to remove carefully all the leaf surfacefree water, because the flattening plate needs to be dry and clean to generate reliable readings. In preliminary assays, not presented, moistened leaves caused unduly low leaf flattening pressure results in comparison with these same leaves measured again, 1 or 2 min later after being surface-dried with a paper towel.

Air permeation as a water status measuring tool. Air flow $(x)$ across the remaining air volumes contained between the leaf and the pressed flattening plate reduces nonlinearly as the applied compression ( $p$ ) increases (Fig. 2A) and this air flow attenuation enabled the adaptation of the flattening method to this wiltmeter portable instrument. The instrument basic procedure of reducing the air flow $(x)$ down to zero to estimate $p_{0}$, however, does not work equally well in all cases and for this reason, it is frequently preferable to estimate $p_{0}$ with some suitable approximation procedure. The chosen approximation method used in this work was the linearization obtained by plotting $1 / p$ versus $x$ (Fig. 2B). The use of this extrapolation method, however, is time-consuming for most postharvest or plant physiology applications. Consequently, in this study, the linearization method was used only as a tool to calculate the $w$ coefficient of each leaf vegetable, which was applied to estimate $p_{0}$ using a single rapid reading along with the coefficient-corrected approximation. For these leaf vegetable crops, the average observed coefficient $(w)$ was 1.06 for crisp lettuce, 1.06 for kale, and 1.03 for chicory. The coefficient-corrected procedure to estimate $p_{0}$ is simple and can be used even in field-oriented studies, because it involves only the rapid reading made at $x_{j}=4 \mathrm{~mm}(1.8$ $\left.\mathrm{mL} \cdot \mathrm{min}^{-1}\right)$. The estimate of $p_{0}$ is then made later with aid of the previously determined $w$ coefficient. Observed $w$ values close to one were considered a favorable result because it indicates that for most field applications, the rapid procedure, even without coefficient correction adjustment, is a valuable estimation that can be used as a leaf wilting index or even as an auxiliary irrigation scheduling index.

It is important to point out that a procedure such as the linearization, or the quadratic, method may become one practical way to implement new portable microprocessed wiltmeters, in which $p_{0}$ will be calculated immediately and more accurately with aid of real-time data acquisition procedures.

The instrument air flow control. When air passage orifices [Fig. 1 (2)] in the flattening plate (Fig. 1) are closed, the air flow reduces with a response time $\left(t_{1 / 2}\right)$ of $\approx 2 \mathrm{~s}$, which is a relatively rapid instrument response time. During a measurement, the instrument response time may be a little more complex variable to be measured, and eventually, it could be a little longer, because it depends on the time the leaf flattening strain occurs under the applied compression stress. With the response time related to the air flow, it is also directly related to the used inlet air pressure $\left(p_{\text {air }}\right)$ that can insufflate an air flow proportional to $p_{\text {air }}$ through the controlling restriction, whereas $p_{\text {air }}$ is small enough for the air to behave nearly as an incompressible liquid (Moore, 1972). Larger $p_{\text {air }}$ values, however, can also be used, but air compressibility is also a relevant nonlinear modulating component for the air flow through the instrument restrictions. Another air flowrelated response time component is the flowmeter manometer, in which response rapidity is inversely related to its internal dead air volume change caused by the liquid column movement during a measurement. To achieve response of a few seconds, the flowmeter used in this wiltmeter was set to work between zero and $90 \mathrm{~mL} \cdot \mathrm{min}^{-1}$ and in this range, the observed internal air volume change in a flowmeter manometer $U$ tube was $\approx 0.4 \mathrm{~mL}$. Additionally, ethanol was used as the manometric fluid because it is less dense and has a much lower surface tension than water, which also helps in attaining a fast and accurate response

The 6-kPa working air pressure $\left(p_{\text {air }}\right)$ used is a small-inlet air pressure considering that a common battery-driven microcompressor typically develops air pressures above $10 \mathrm{kPa}$, and as a consequence, $6 \mathrm{kPa}$ was easily adjusted in an escape valve [Fig. 1 (10)]. After defining $p_{\text {air }}$, the instrument air restrictions (Fig. 1) were estimated as follows: the flowmeter restriction $R_{2}$ [Fig. 1 (3)] is a plastic capillary tube cut to allow an air flow of $90 \mathrm{~mL} \cdot \mathrm{min}^{-1}$ with a $200 \mathrm{~mm}$ of pressure difference at its reading in an alcohol manometric column. The air inlet restriction $R_{I}$ [Fig. 1 (11)], on the other hand, is set to develop a $200-\mathrm{mm}$ reading at the flowmeter, when was fed by an adjusted $6.0-\mathrm{kPa}$ air pressure source in the opened wiltmeter. Both $R_{1}$ and $R_{2}$ are prepared by cutting pieces of a plastic capillary tube with an internal diameter of $\approx 110 \mu \mathrm{m}$. The air restrictions $R_{I}$ and $R_{2}$ work in series with the leaf/flattening plate air restriction $R_{L}$ (Fig. 3).
Consequently, as the wiltmeter-applied pressure increases, $R_{L}$ also increases, as it is indicated by the air flow reduction (Fig. 2A). When $R_{L}$ becomes much greater than $R_{l}$ plus $R_{2}$, then the applied air pressure $\left(p_{\text {air }}\right)$ is all dissipated at the restriction $R_{L}$.

Instrument features. This instrument is suitable to measure near laminar vegetable samples such as leaves or segmented organs with thickness ranging from $0.050 \mathrm{~mm}$ to $2 \mathrm{~mm}$. For measurement, these laminar structures are hydraulic-compressed with aid of a membrane [Fig. 1 (6)], which should be elastic and thin to uniformly compress the organ against the flattening plate, across a free circular area, with a diameter of $15 \mathrm{~mm}$. A $500-\mu \mathrm{m}$ flexible polybutene rubber membrane, which is also robust and durable, is suitable to perform this function. It is also important to point out that this membrane can inflate excessively causing rupture if the wiltmeter is not properly closed with the bolt/screw [Fig. 1 (7)] before compressing the leaf. The use of thicker and more robust membranes can cause uneven compression for veined leaves, whereas the use of thinner and more flexible $200-\mu \mathrm{m}$ latex membranes, which can apply a more uniform compression, even for small veins, are fragile and short-lived. For specific fine experimental work, however, such thin membranes can be installed, because they are fixed and sealed between a fixing plate and the instrument base.

The flattening plate (Fig. 1) with a finely engraved surface net made of $10-$ to $30-\mu \mathrm{m}$ deep obtuse indentations is another essential instrument feature. The engraved surface enables the measurement of smooth surfaced samples, because it helps in assuring that the air passages are only blocked after the compressed leaf surface is molded to the flattening plate shape. This engraved network also helps in allowing measurement of small samples with a minimum length of $15 \mathrm{~mm}$ and a minimal width of $\approx 6 \mathrm{~mm}$. During a measurement, the adaxial leaf side, which is usually the most regular one, is the side that should preferably be placed in contact with the flattening plate, considering that large veins and other leaf irregularities should not be placed directly under the central flattening plate mechanism area.

Instrument gauging. In the wiltmeter instrument comparison against the cell turgor

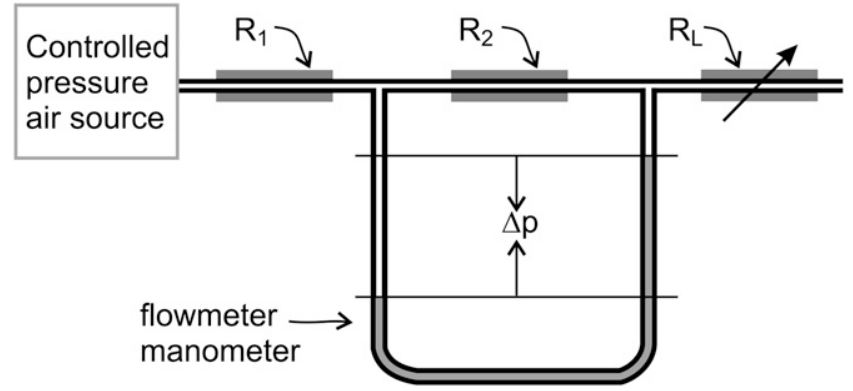

Fig. 3. Restrictions that modulate the air flow driven by a controlled inlet air pressure source $(6.0 \mathrm{kPa})$ in the wiltmeter instrument. $R_{1}=$ inlet air flow restriction; $R_{2}=$ flow meter restriction; $R_{L}=$ variable leaf/ flattening plate interface restriction. 

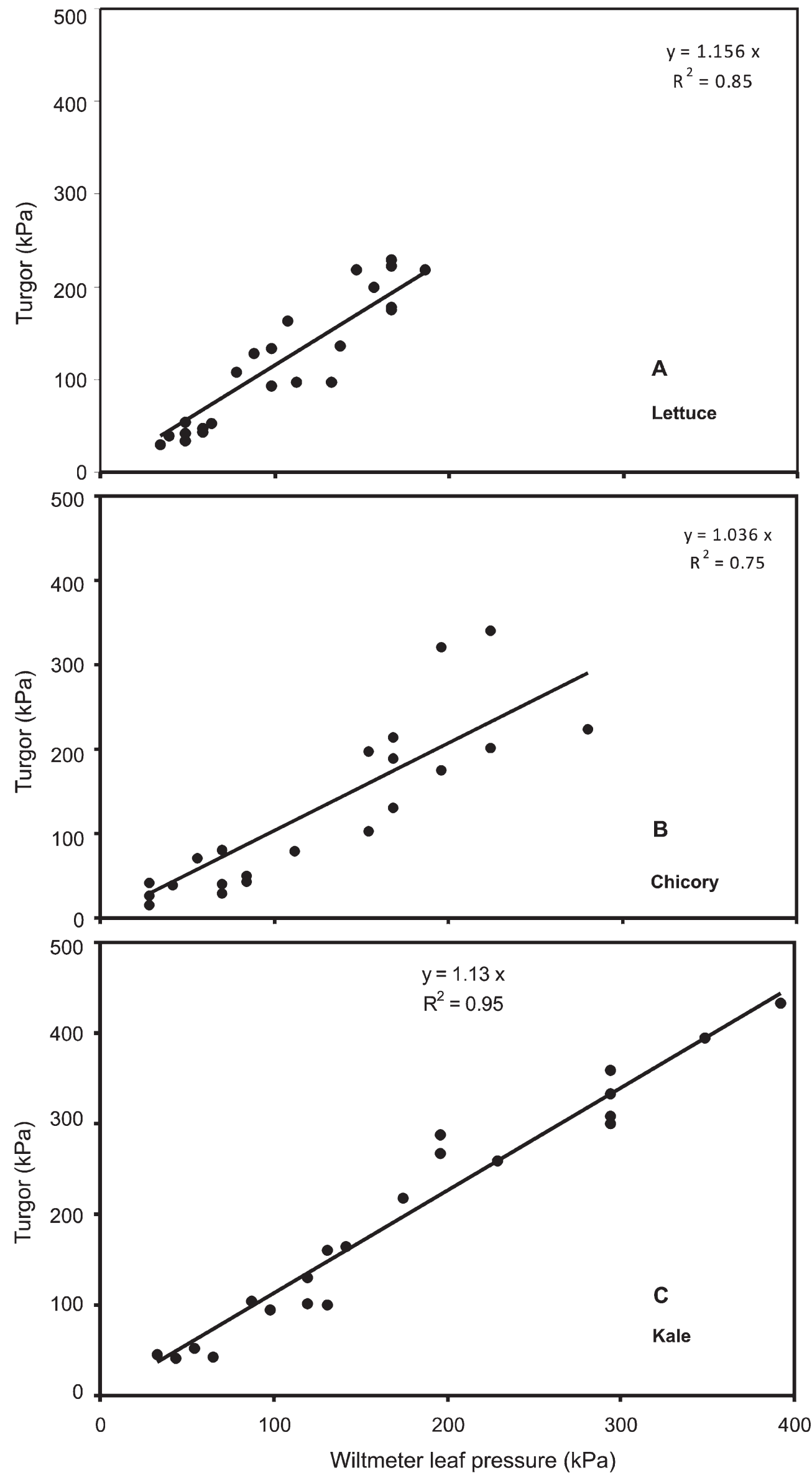

Fig. 4. Relationship between leaf flattening pressure, measured with the wiltmeter instrument, and cell turgor pressure, measured with the pressure probe. (A) Lettuce, (B) chicory, and (C) kale. 
pressure probe (Fig. 4), it can be observed that readings by these two methods were proportional with slopes of 1.16 for lettuce, 1.13 for kale, and 1.04 for chicory. These values are consistent with the fact that the flattening method conceptually should generate pressure readings smaller than the cell turgor pressure measured with the pressure probe, except for limiting tissues in which the cell wall thickness and the intercellular air volumes could be considered vanishingly small (Calbo and Nery, 2001). The percentage of intercellular air volume $(\mathrm{v} / \mathrm{v})$ in the leaf is expressive and for most crops it is in the range between $20 \%$ and $30 \%$ (Spector, 1956). Estimates of the cell wall thickness can be assessed in terms of percentage of apoplastic water volume, which for Brassica leaves is on the order of $10 \%$ of the leaf volume (Husted and Schjoerring, 1995). Consequently, despite the relevant apoplasmic and intercellular air volumes of the leaves, the wiltmeter produces leaf pressure estimates that are very close to the leaf cell turgor pressure as measured by the pressure probe method, which is an indication that this instrument can be used for quantitative studies devoted to postharvest and other field experiments where portability, rapidity, and robustness are crucial requirements.

Measuring leaf turgidity with the portable flattening procedures herein described represents progress over current simple subjective sensory procedures that are used to evaluate water status in postharvest, irrigation scheduling, and in some plant physiology applications. The closeness of the wiltmeter instrument readings to the leaf turgor pressure measured with the pressure probe makes this flattening method a practical field substitute for the pressure probe, which can be easily used in the field for most of the commercially relevant crops during quantitative evaluations of wilting, freshness, and turgor pressure needed for agronomic and ecological applications.

\section{Literature Cited}

Berstein, Z. and I. Lustig. 1981. A new method of firmness measurement of grape berries and other juicy fruits. Vitis 20:15-21.

Bernstein, Z. and I. Lustig. 1985. Determination of the mechanical properties of the grape berry skin by hydraulic measurements. Scientia Hort. 25:129-136.

Boyer, J.S. 1985. Water transport. Annu. Rev. Plant Physiol. 36:473-516.

Calbo, A.G. 1991. Desenvolvimento de um equipamento para medir turgor em folhas e outros órgãos (Turgômetro). Sociedade Brasileira de Fisiologia Vegetal. Viçosa, Brazil, 24-28 Feb. 1991. 3rd Congr. Bras. Fisiol. Veg. p. 13.

Calbo, A.G. and M.E. Calbo. 1989. Medição e importância do potencial de parede. R. Bras. Fisiol. Veg. 1:41-45.

Calbo, A.G. and A.A. Nery. 1995. Medida de firmeza em hortaliças pela técnica de aplanação. Hort. Bras. 13:14-18.

Calbo, A.G. and A.A. Nery. 2001. Compression induced intercellular shaping for some geometric cellular lattices. Braz. Arch. Biol. Technol. 44:41-48.

Calbo, A.G., A.A. Nery, and P.S.P. Herrmann. 1995. Intercellular deformation in compressed organs. Ann. Bot. (Lond.) 76:365-370.

Calbo, A.G. and J.D.C. Pessoa. 2009. Applanation system for evaluation of cell pressure dependent firmness on leaves and soft organs flat face segments. WO Patent 009850A1.

Calbo, A.G., W.L.C. Silva, and A.C. Torres. 1989. Ajuste de funções não lineares de crescimento. R. Bras. Fisiol. Veg. 1:9-18.

Calbo, M.E.R. and J.A.P.V. Moraes. 1997. Fotossíntese, condutância estomática, transpiração e ajustamento osmótico de plantas de buriti submetidas a estresse hídrico. R. Bras. Fisiol. Veg. 9:117-123.

Caron, V.C., A.P. Jacomino, and R.A. Kluge. 2003. Conservação de cenouras 'Brasília' tratadas com cera. Hort. Bras. 21:597-600.

Heathcote, D.G., J.R. Etherington, and F.I. Woodward. 1979. An instrument for non-destructive measurements of the pressure potential (turgor) of leaf cells. J. Expt. Bot. 30:811-816.

Hüsken, D., E. Steudle, and V. Zimmermann. 1978. Pressure probe technique for measuring water relations in higher plants. Plant Physiol. 61:158163.

Husted, S. and J.K. Schjoerring. 1995. Apoplastic $\mathrm{pH}$ and ammonium concentration in leaves of Brassica napus L. Plant Physiol. 109:14531460.

Kluge, R.A., A.C.C. Antonini, W.G.R. Robles, J.T Neto, A.P. Jacomino, and J.A.S. Filho. 1999. Avaliação de cultivares de berinjela em armazenamento refrigerado. Sci. Agr. 56:1045-1050.

Lintilhac, P.M. and J.O. Outwater. 1998. Method and apparatus for determining a contact area between a probe and a specimen. Invention patent WO 98/14754.

Lintilhac, P.M., C. Wei, J.J. Thanguay, and J.O. Outwater. 2000. Ball tonometry: A rapid, nondestructive method for measuring cell turgor pressure in thin-walled plant cells. J. Plant Growth Regul. 19:90-97.

Moore, W.J. 1972. Physical chemistry. PrenticeHall, Englewood Cliffs, NJ.

Nizio, D.A.C., W.R. Maluf, A.R. Figueira, D.W. Nogueira, V.F. Silva, and Á.C. Gonçalves Neto. 2008. Caracterização de genótipos de tomateiro resistentes a begomovírus por marcador molecular co-dominante ligado ao gene $T y$-1. Pesquisa Agropecu. Bras. 43:1699-1705.

Nonami, H., J.S. Boyer, and E. Steudle. 1987. Pressure probe and isopiestic psychrometer measure similar turgor. Plant Physiol. 83:592-595.

Pessoa, J.D.C. and A.G. Calbo. 2004. Pressure measurement using thermal properties of materials. Rev. Sci. Instrum. 75:2213-2215.

Scholander, P.F., H.T. Hammel, E.A. Hemingsen, and E.D. Bradstreet. 1964. Hydrostatic pressure and osmotic potential in leaves of mangroves and some other plants. Proc. Natl. Acad. Sci. USA 52:119-125.

Spector, W.S. 1956. Handbook of biological data. Saunders, Philadelphia, PA.

Turner, N.C. and M.A. Sobrado. 1983. Evaluation of a non-destructive method for measuring turgor pressure in Helianthus. J. Expt. Bot. 34:15621568.

Zimmermann, D., R. Reuss, M. Westhoff, P. Geßner, W. Bauer, E. Bamber, F.W. Bentrup, and U. Zimmermann. 2008. A novel, noninvasive, online-monitoring, versatile and easy plant-based probe for measuring leaf water status. J. Expt. Bot. 59:3157-3167. 